\title{
National and rural-urban prevalence and determinants of early initiation of breastfeeding in India
}

\author{
Praween Senanayake ${ }^{1}$, Elizabeth O'Connor ${ }^{2}$ and Felix Akpojene Ogbo ${ }^{1,3^{*}}$ (D)
}

\begin{abstract}
Background: Early initiation of breastfeeding (EIBF) reduces the risk of neonatal mortality. Previous studies from India have documented some factors associated with EIBF. However, those studies used data with limited sample size that potentially affect the application of the evidence. Additionally, the effectiveness of national breastfeeding programmes requires up-to-date analysis of new and robust EIBF data. The present study aimed to investigate the prevalence and determinants of EIBF in India and determine to what extent these factors differ by a mother's residence in the rural or urban area.
\end{abstract}

Methods: This study used information from a total weighted sample of 94,401 mothers from the 2015-2016 India National Family Health Survey. Multivariate logistic regression was used to investigate the association between the study factors and EIBF in India and rural-urban populations, after adjusting for confounders and sampling weight.

Results: Our analysis indicated that $41.5 \%$ (95\% confidence interval (Cl): 40.9-42.5, $P<0.001$ ) of Indian mothers initiated breastfeeding within 1-h post-birth, with similar but significant different proportions estimated for those who resided in rural $(41.0,95 \% \mathrm{Cl}: 40.3-41.6, P<0.001)$ and urban $(42.9,95 \% \mathrm{Cl}: 41.7-44.2, \mathrm{P}<0.001)$ areas. Mothers who had frequent health service contacts and those with higher educational attainment reported higher ElBF practice. Multivariate analyses revealed that higher educational achievement, frequent antenatal care visits and birthing in a health facility were associated with EIBF in India and rural populations (only health facility birthing for urban mothers). Similarly, residing in the North-Eastern, Southern, Eastern and Western regions were also associated with EIBF. Birthing through caesarean, receiving delivery assistance from non-health professionals and residing in rural areas of the Central region were associated with delayed EIBF in all populations.

Conclusion: We estimated that more than half of Indian mothers delayed breastfeeding initiation, with different rural-urban prevalence. Key modifiable factors (higher maternal education and frequent health service contacts) were associated with EIBF in India, with notable difference in rural-urban populations. Our study suggests that targeted and well-coordinated infant feeding policies and interventions will improve ElBF for all Indian mothers.

Keywords: Early initiation, Breastfeeding, Children, India, Rural, Urban

\footnotetext{
* Correspondence: felgbo@yahoo.co.uk

${ }^{1}$ Translational Health Research Institute (THRI), School of Medicine, Western Sydney University, Campbelltown Campus, Locked Bag 1797, Penrith, NSW 2571, Australia

${ }^{3}$ Prescot Specialist Medical Centre, Welfare Quarters, Makurdi, Benue State, Nigeria

Full list of author information is available at the end of the article
}

(c) The Author(s). 2019 Open Access This article is distributed under the terms of the Creative Commons Attribution 4.0 International License (http://creativecommons.org/licenses/by/4.0/), which permits unrestricted use, distribution, and reproduction in any medium, provided you give appropriate credit to the original author(s) and the source, provide a link to the Creative Commons license, and indicate if changes were made. The Creative Commons Public Domain Dedication waiver (http://creativecommons.org/publicdomain/zero/1.0/) applies to the data made available in this article, unless otherwise stated. 


\section{Background}

Early initiation of breastfeeding (EIBF, defined as the provision of only breast milk to the newborn within the first hour of birth) has been well-documented to reduce the risk of neonatal mortality [1-4]. The protective effect of EIBF is based on the immunological components of the breast milk $[5,6]$, the improvement in exclusive breastfeeding [7-9] and the avoidance of prelacteal foods that deprive newborns of colostrum, rich in nutrients and immunoglobulins needed to fight disease [10, 11]. Despite the evidence supporting the protective effect of EIBF, the prevalence of EIBF remains low (an average of $50 \%)$ in many developing countries [12, 13], where the majority of preventable neonatal deaths exist [6], compared to the global recommendation of 90\% [14]. Although India has made some progress in increasing EIBF rates in the past decade [15], evidence from regional areas indicated that the proportion of mothers who put their babies to the breast within the first hour of birth remains below the expected level, ranging from $36 \%$ [16] to $42 \%[17,18]$.

A previous national study based on the 2005-2006 India National Family Health Survey (NFHS-3) [19] has elucidated factors associated with delayed EIBF in India. These attributes included caesarean delivery and living in the Central region. In contrast, health facility birthing, listening to the radio, frequent antenatal visits and living in the Northeastern, Southern or Western region were associated with increased likelihood of EBIF in India [19]. However, findings from these studies may not provide a current evidence base on EIBF in India. Similarly, it is unclear whether EIBF behaviour has changed in the past decade because of the implementation of a number of maternal and child health $(\mathrm{MCH})$ interventions (e.g. Reproductive, Maternal, Newborn, Child, and Adolescent Health [RMNCH+A] Strategy [20], National Rural Health Mission, NRHM [21] and National Urban Health Mission under the National Health Mission [22]) and sample size differences.

In the NFHS-3, approximately 110,000 households were selected nationally from 1 billion people based on the 2001 census frame [23] compared to nearly 572,000 selected households from 1.2 billion people based on the 2011 census list in the 2015-2016 India National Family Health Survey (NFHS-4), [24, 25], which is the data source for the present study. Notably, the NFHS-4 has been documented to serve as the benchmark for future national household surveys in India [24-26]. The availability of new and more nationally representative data calls for up-to-date evidence to inform EIBF programmes and help policy decision-makers and health administrators provide targeted breastfeeding policies and interventions.

Additionally, the past nationwide study from India did not examine the differences in the factors associated with EIBF in both rural and urban populations of India given the implementation of both rural- and urbanspecific $\mathrm{MCH}$ interventions [21, 22]. Reports have indicated that there are significant disparities in socioeconomic status and health service access in India, with subsequent impact on disease burden and health status [27-30], and whether these factors have an impact on EIBF remains unclear. An investigation into the factors associated with EIBF across rural-urban residence is crucial to understand where additional intervention is needed to meet the national and subnational breastfeeding targets. The present study aimed to investigate the prevalence and determinants of EIBF at the national level in India, along with those for rural-urban populations.

\section{Methods}

\section{Data sources}

The NFHS-4 data, also known as the India Demographic and Health Survey (DHS) were used for this study, collected by the International Institute for Population Sciences (IIPS), Mumbai through the Ministry of Health and Family Welfare (MoHFW), Government of India. The Inner City Fund (ICF) International, Maryland, USA provided technical assistance in data collection efforts. Infant and young child feeding practices (including EIBF) data, as well as socio-demographic and household characteristics were collected from a nationwide representative sample of women aged 15-49 years. The response rates in the interview varied across the states and territories of India, from $94.0 \%$ in Andhra Pradesh and West Bengal [24, 25] to $99.6 \%$ in Bihar [26].

Using a two-stage sampling design, a total sample of approximately 572,000 households (including women aged 15-49 years and men aged 15-54 years) across both rural and urban areas was obtained for the NFHS-4, with villages and census enumeration blocks as the primary sampling units, respectively. The NFHS-4 was based on the 2011 census, where an urban area constitutes statutory towns, census towns and outgrowths, while all areas other than urban were rural. The basic unit for rural areas is the revenue village. Specific exposition of what statutory towns, census towns and outgrowths mean are provided elsewhere [31].To obtain the sample of mothers who initiated breastfeeding within the first hour of birth, we restricted our analyses to the youngest living children aged less than 24 months, living with respondent (women aged 15-49 years) to reduce the potential effect of recall bias [32]. The total weighted sample was 94,104 for the total population of India, 68, 260 for rural areas and 25,843 for urban areas. Additional information on the survey methodology is provided in the final India DHS reports [24, 25]. 


\section{Outcome variable}

In the present study, early or timely initiation of breastfeeding was measured as the proportion of infants $0-23$ months of age who were put to the breast within the first hour of birth, in line with the World Health Organisation and United Nations Children's Funds (WHO/ UNICEF) definitions for assessing infant and young child feeding practices [33].

\section{Study variables}

We selected study factors based on the evidence from previous studies [34-36], including socio-economic, individual and health service factors. Socio-economic factors included the mother's highest educational level and employment status, household wealth index and father's highest educational level. The household wealth index was derived from a principal components analysis conducted by the IIPS and ICF International and was calculated as a score of ownership household assets such as transportation device, ownership of durable goods and household facilities [37]. The household wealth index was classified into five categories (quintiles), and each household was assigned to one of these wealth index categories, namely: poorest, poorer, middle, rich and richest. We re-categorised the bottom $40 \%$ of households as poor households, the next $40 \%$ as the middle households and the top $20 \%$ as rich households to provide sufficient numbers in each category, consistent with previously published studies $[9,35,38]$. Individual factors included maternal age, the gender of the child, preceding birth interval and birth order of the child (the position of the child in the family).

Health service factors included the number of antenatal care (ANC) visits, the place of delivery, the mode of delivery and the type of delivery assistance. Delivery assistance received from non-health professionals (i.e., assistance from outside the health facility) was categorised as either traditional birth attendants (TBAs or Dai in India) or other non-health professionals. A traditional birth attendant is commonly a woman, who assists the mother during childbirth and who originally acquired those birthing skills by working with other traditional birth attendants or by delivering babies herself [39]. Other non-health professionals included relatives, friends, no one and others, while health professionals included doctors, auxiliary nurse midwives, nurses, midwives, and lady health visitors [40].

Given that India is a federal union that comprise 29 states and 7 union territories, with a total of 36 entities, we also considered geographical region in the analyses. The states and union territories are aggregated into six zonal councils (North, South, East, West, Central and North-Eastern) to facilitate inter-state cooperation with regard to better socio-political and economic collaboration, and health system strengthening $[19,20]$.

\section{Statistical analysis}

Our preliminary analyses involved the calculation of the frequencies (and percentages) of the study factors for the overall population and rural-urban residence, prevalence of EIBF in India and rural-urban residence, as well as a series of frequencies and cross-tabulations to estimate the prevalence of EIBF by the study factors for all three locations (overall population and rural-urban residence). This was followed by univariate logistic regression analysis to examine factors associated with EIBF in India and rural-urban residence. We only entered into the multivariate models, those study variables with $P$ value $<0.05$ in univariate models to estimate the factors associated with EIBF in India and rural-urban residence. Univariate and multivariate odds ratios (ORs) and their 95\% confidence intervals were reported in the present study for all three locations. All analyses were performed using the 'svy' command for calculation of counts and percentages in Stata 15.0 (Stata Corporation, College Station, Texas, USA) to adjust for sampling weight, clustering and stratification.

\section{Ethics}

The Ethics Review Board at the International Institute for Population Sciences, Mumbai, India granted the DHS project ethical approvals before the surveys were conducted, with written informed consent obtained from participants during the surveys. Approval was sought from Measure DHS and permission was granted for this use.

\section{Results}

\section{Characteristics of the study population}

In the total weighted sample of 94,104 women aged 1549 years, 59.3\% had secondary and higher education in the total population, $13.5 \%$ had primary education and 27.3\% had no education. In rural areas, a little above half (53.4\%) of mothers had secondary and higher education, while $14.6 \%$ had primary education and $32.0 \%$ had no education. In contrast, the majority $(74.6 \%)$ of mothers had secondary and higher education in the urban population, while $10.6 \%$ had primary education and $14.8 \%$ had no education [Additional file 1].

\section{Prevalence of EIBF in the study population}

The proportion of mothers who initiated breastfeeding within the first hour of birth for children aged 0-23 months was 41.5\% [95\% confidence interval (CI): 40.942.5, $P<0.001$ ] in the total population [Table 1]. The study found a higher proportion of mothers with secondary and above education level who put their babies 
Table 1 Prevalence of early initiation of breastfeeding (EIBF) by study factors among children aged 0-23 months in India, NFHS 2015-2016

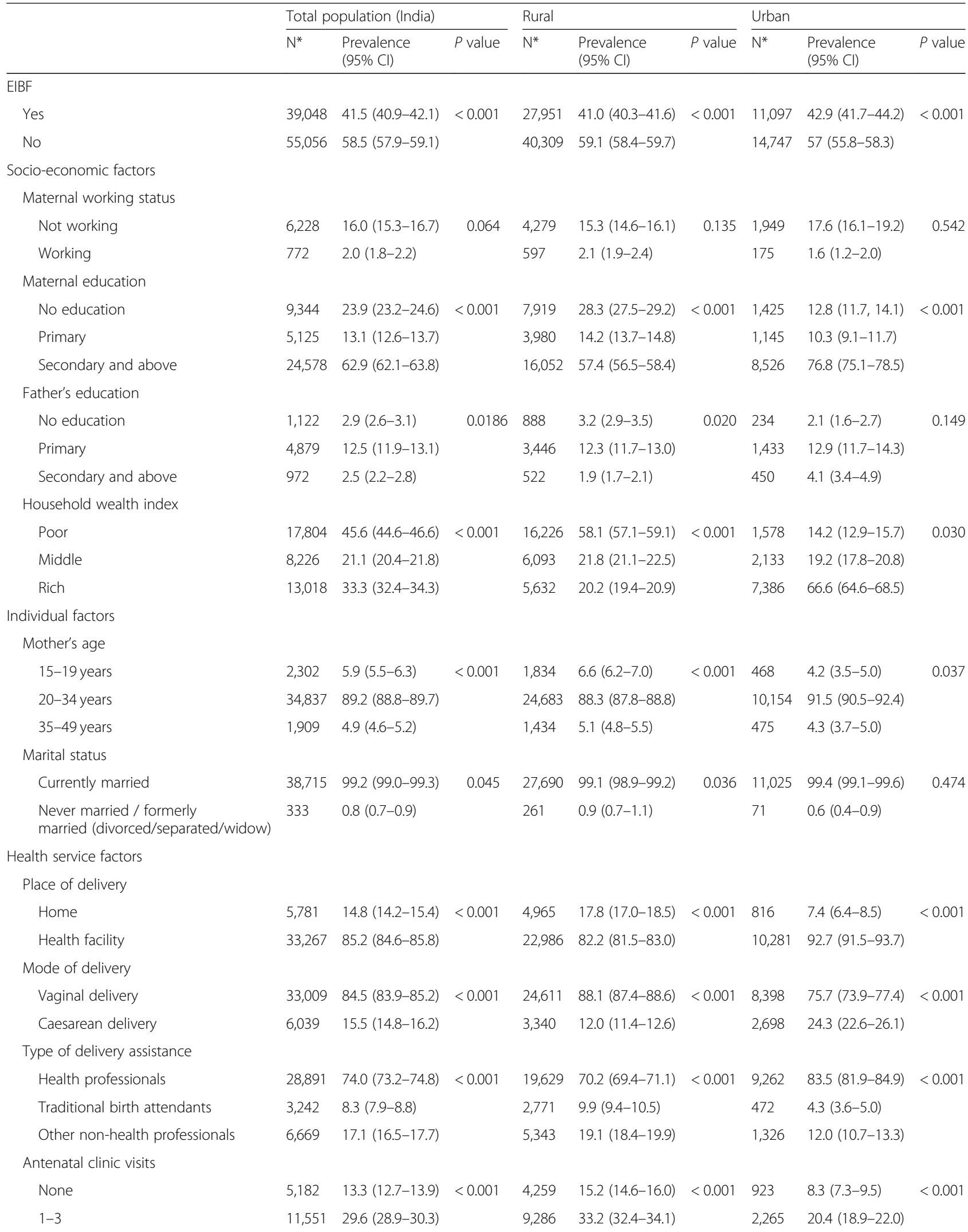


Table 1 Prevalence of early initiation of breastfeeding (EIBF) by study factors among children aged 0-23 months in India, NFHS 2015-2016 (Continued)

\begin{tabular}{|c|c|c|c|c|c|c|c|c|c|}
\hline & \multicolumn{3}{|c|}{ Total population (India) } & \multicolumn{3}{|l|}{ Rural } & \multicolumn{3}{|l|}{ Urban } \\
\hline & $\mathrm{N}^{*}$ & $\begin{array}{l}\text { Prevalence } \\
(95 \% \text { Cl) }\end{array}$ & $P$ value & $\mathrm{N}^{*}$ & $\begin{array}{l}\text { Prevalence } \\
(95 \% \text { CI) }\end{array}$ & $P$ value & $\mathrm{N}^{*}$ & $\begin{array}{l}\text { Prevalence } \\
(95 \% \text { CI) }\end{array}$ & $P$ value \\
\hline Four or more & 22,015 & $56.4(55.5-57.3)$ & & 14,211 & $50.8(49.8-51.9)$ & & 7,805 & $70.3(68.5-72.0)$ & \\
\hline \multicolumn{10}{|l|}{ Environmental factor } \\
\hline \multicolumn{10}{|c|}{ Geographical region } \\
\hline North & 3,853 & $9.9(9.3-10.4)$ & $<0.001$ & 2,618 & $9.4(8.8-9.9)$ & $<0.001$ & 1,235 & $11.1(10.0-12.4)$ & $<0.001$ \\
\hline South & 8,527 & $21.8(20.8-22.9)$ & & 5,017 & $18.0(16.9-19.0)$ & & 3,510 & $31.6(29.7-33.6)$ & \\
\hline East & 10,321 & $26.4(25.3-27.6)$ & & 8,503 & $30.4(29.2-31.7)$ & & 1,818 & $16.4(14.8-18.1)$ & \\
\hline West & 6,440 & $16.5(15.4-17.7)$ & & 3,710 & $13.3(12.3-14.4)$ & & 2,730 & $24.6(22.3-27.1)$ & \\
\hline Central & 7,790 & $20.0(19.2-20.7)$ & & 6,260 & $22.4(21.5-23.4)$ & & 1,530 & $13.8(12.8-14.9)$ & \\
\hline North-East & 2,117 & $5.4(5.1-5.8)$ & & 1,843 & $6.6(6.1-7.1)$ & & 274 & $2.5(2.2-2.7)$ & \\
\hline
\end{tabular}

Prevalence (EIBF): The proportion of children 0-23 months of age who were put to the breast within one hour of birth; $\mathrm{N}^{*}$ : the weighted total number varies between categories due to missing data

to the breast within the first hour of birth in the total population $[62.9 \% \quad(95 \%$ CI: $62.1-63.8), \quad P<0.001]$. Mothers who received delivery assistance from health professionals also reported a higher proportion of EIBF compared to those who were assisted by TBAs or other non-professionals in India. The prevalence of early initiation of breastfeeding was $41.0 \%$ (95\% CI: 40.3-41.6, $\mathrm{P}<0.001)$ in the rural population and $42.9 \%(95 \% \mathrm{CI}$ : 41.7-44.2, $P<0.001$ ) in the urban population [Table 1], reflecting a significant difference between EIBF prevalence among mothers who resided in rural areas compared to those who lived in urban areas of India. There was a higher proportion of EIBF mothers with secondary and above education level in the urban population (76.8, 95\% CI: $75.1-78.5 \%, P<0.001)$ compared to the rural population (57.4, 95\% CI: 56.5-58.4\%, $\mathrm{P}<0.001$ ).

\section{Determinants of early initiation of breastfeeding in India}

In the total population of India, mothers with secondary and above education were significantly more likely to timely initiate breastfeeding compared to mothers with no schooling [Adjusted Odds ratio (AOR): 1.40, 95\% CI: 1.24-1.59; $\mathrm{P}<0.001$ ) [Table 2]. Conversely, higher partner education was associated with delayed EIBF (AOR: $0.75,95 \% \mathrm{CI}: 0.62-0.91 ; P=0.004$ for secondary and above education). Women who had been formerly married were more likely to initiate breastfeeding within $1 \mathrm{~h}$ of birth (AOR: 2.13, 95\% CI: 1.31-3.46; $P=0.002$ ). Caesarean birth was associated with delayed EIBF in the Indian population (AOR: 0.53 , 95\% CI: $0.49-0.56 ; P<$ 0.001 ). Mothers who were assisted by TBAs or other non-health professionals were less likely to practice EIBF compared to those who received assistance from health professionals (AOR: 0.87, 95\% CI: 0.80-0.94; $P<0.001$ and AOR: 0.84, 95\% CI: 0.79-0.90; $\mathrm{P}<0.001$ respectively). Mothers who received four or more antenatal care visits and those who gave birth in a health facility were more likely to practice EIBF compared to those who received no ANC visits and those who birthed at home (AOR: 1.43 , 95\% CI: $1.33-1.55 ; P<0.001$ and AOR: 1.22 , 95\% CI: 1.14-1.31; $P<0001$, respectively). Concerning geographic regions, mothers who resided in the NorthEast were more likely to initiate breastfeeding in the first-hour post-birth compared to those who resided in the North (AOR: 3.64, 95\% CI: 2.89-4.60; $P<0.001$ ). Residence in the Southern, Eastern and Western regions was significantly associated with EIBF practice in India [Table 2].

\section{Determinants of early initiation of breastfeeding in rural- urban India}

Among the rural population, higher maternal education increased the odds of EIBF (AOR: 1.40, 95\% CI: 1.231.59; $\mathrm{P}<0.001$ for secondary and above education) [Table 3]. Rural mothers who had previously been married were more likely to practice EIBF (AOR: 2.00, 95\% CI: $1.17-3.41, P=0.011)$. Urban mothers with husbands who had secondary and above education were also less likely to initiate breastfeeding compared to those who had no education (AOR: 0.59, 95\% CI: $0.37-0.94 ; P=$ 0.028). The association between partner education and EIBF was attenuated in rural areas (AOR: 0.81, 95\% CI: $0.66-1.00 ; P=0.050$ ).

Both rural and urban mothers who gave birth in health facilities had a higher likelihood of engaging in EIBF (AOR: $1.19,95 \%$ CI: $1.11-1.27 ; P<0.001$ for rural and AOR: 1.45 , 95\% CI: $1.18-1.78$; P $<0.001$ for urban). Caesarean birth and delivery assistance from TBAs or other non-health professionals were associated with decreased odds of EIBF in rural areas (AOR: 0.54, 95\% CI: 0.500.58; $P<0.001$ for caesarean births; AOR: $0.88,95 \% \mathrm{CI}$ : $0.81-0.96 ; P=0.002$ for TBAs and AOR: $0.85,95 \% \mathrm{CI}$ : 
Table 2 Determinants of early initiation of breastfeeding in the total population of Indian mothers, NFHS 2015-2016

\begin{tabular}{|c|c|c|c|c|c|c|}
\hline & Unadjusted OR & $95 \% \mathrm{Cl}$ & $P$ value & Adjusted $^{\mathrm{a}} \mathrm{OR}$ & $95 \% \mathrm{Cl}$ & $P$ value \\
\hline \multicolumn{7}{|l|}{ Socioeconomic factors } \\
\hline \multicolumn{7}{|l|}{ Maternal working status } \\
\hline Not working & 1.00 & & & 1.00 & & \\
\hline Working & 0.88 & $0.76-1.00$ & 0.061 & 0.87 & $0.75-1.00$ & 0.044 \\
\hline \multicolumn{7}{|l|}{ Maternal education } \\
\hline No education & 1.00 & & & 1.00 & & \\
\hline Primary & 1.19 & $1.11-1.27$ & $<0.001$ & 1.09 & $0.93-1.26$ & 0.285 \\
\hline Secondary and above & 1.38 & $1.32-1.44$ & $<0.001$ & 1.40 & $1.24-1.59$ & $<0.001$ \\
\hline \multicolumn{7}{|l|}{ Father's education } \\
\hline No education & 1.00 & & & 1.00 & & \\
\hline Primary & 1.12 & $1.00-1.27$ & 0.058 & 0.95 & $0.83-1.08$ & 0.449 \\
\hline Secondary and above & 0.95 & $0.80-1.12$ & 0.514 & 0.75 & $0.62-0.91$ & 0.004 \\
\hline \multicolumn{7}{|l|}{ Individual factors } \\
\hline \multicolumn{7}{|l|}{ Marital status } \\
\hline Currently married & 1.00 & & & 1.00 & & \\
\hline Never married / formerly married (divorced/separated/widow) & 1.22 & $1.00-1.48$ & 0.046 & 2.08 & $1.30-3.35$ & 0.002 \\
\hline \multicolumn{7}{|l|}{ Preceding birth interval } \\
\hline No previous birth & 1.00 & & & 1.00 & & \\
\hline$<24$ months & 0.99 & $0.94-1.05$ & 0.819 & 1.16 & $1.02-1.34$ & 0.027 \\
\hline$>24$ months & 1.06 & $1.01-1.102$ & 0.011 & 1.15 & $1.03-1.28$ & 0.010 \\
\hline \multicolumn{7}{|l|}{ Health Service factors } \\
\hline \multicolumn{7}{|l|}{ Mode of delivery } \\
\hline Vaginal delivery & 1.00 & & & 1.00 & & \\
\hline Caesarean delivery & 0.66 & $0.62-0.70$ & $<0.001$ & 0.53 & $0.49-0.56$ & $<0.001$ \\
\hline \multicolumn{7}{|l|}{ Type of delivery assistance } \\
\hline Health professionals & 1.00 & & & 1.00 & & \\
\hline Traditional birth attendants & 0.72 & $0.67-0.77$ & $<0.001$ & 0.87 & $0.80-0.94$ & $<0.001$ \\
\hline Other non-health professionals & 0.74 & $0.70-0.78$ & $<0.001$ & 0.84 & $0.79-0.90$ & $<0.001$ \\
\hline \multicolumn{7}{|l|}{ Antenatal clinic visits } \\
\hline None & 1.00 & & & 1.00 & & \\
\hline $1-3$ & 1.14 & $1.07-1.21$ & $<0.001$ & 0.98 & $0.91-1.05$ & 0.531 \\
\hline Four or more & 1.65 & $1.55-1.76$ & $<0.001$ & 1.43 & $1.33-1.55$ & $<0.001$ \\
\hline \multicolumn{7}{|l|}{ Place of delivery } \\
\hline Home & 1.00 & & & 1.00 & & \\
\hline Health facility & 1.43 & $1.36-1.51$ & $<0.001$ & 1.22 & $1.14-1.31$ & $<0.001$ \\
\hline \multicolumn{7}{|l|}{ Environmental factor } \\
\hline \multicolumn{7}{|l|}{ Geographical region } \\
\hline North & 1.00 & & & 1.00 & & \\
\hline South & 2.05 & $1.89-2.23$ & $<0.001$ & 1.88 & $1.57-2.25$ & $<0.001$ \\
\hline East & 1.50 & $1.39-1.61$ & $<0.001$ & 1.50 & $1.26-1.78$ & $<0.001$ \\
\hline West & 2.43 & $2.20-2.68$ & $<0.001$ & 1.92 & $1.53-2.40$ & $<0.001$ \\
\hline Central & 0.85 & $0.80-0.91$ & $<0.001$ & 0.87 & $0.75-1.01$ & 0.070 \\
\hline North East & 3.50 & $3.17-3.86$ & $<0.001$ & 3.64 & $2.89-4.60$ & $<0.001$ \\
\hline
\end{tabular}




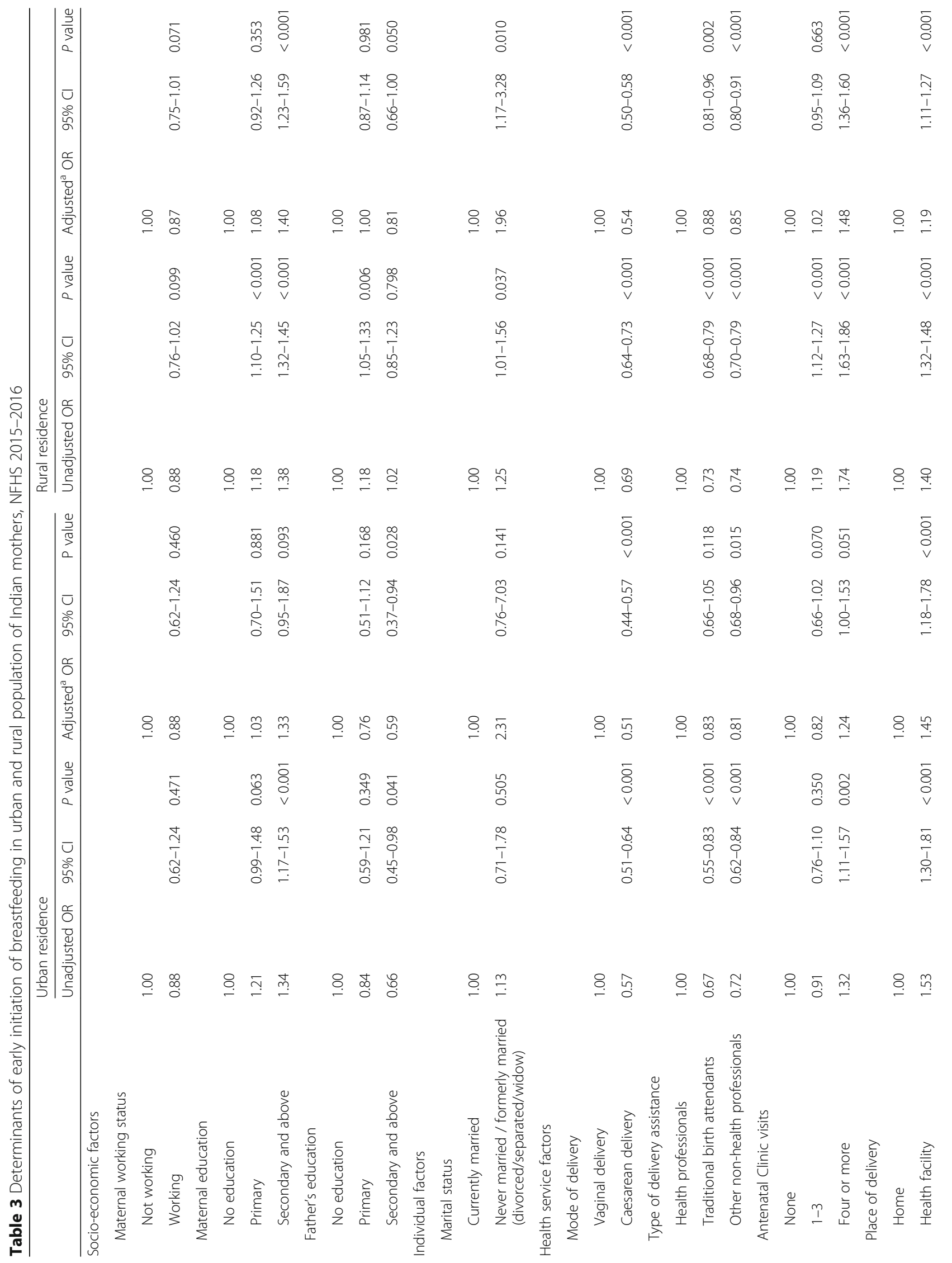




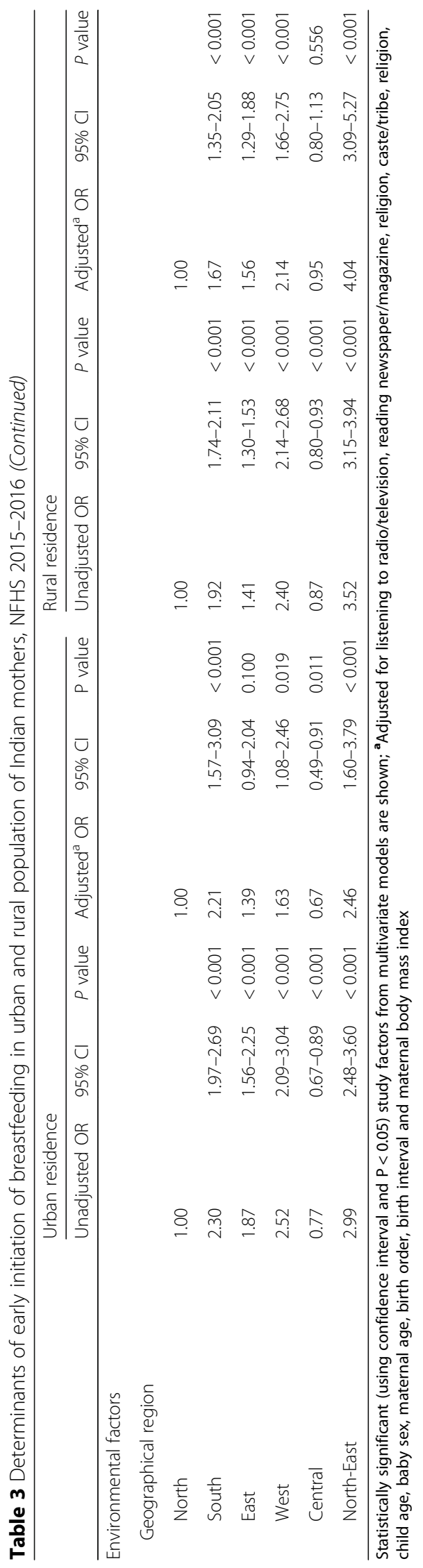


$0.80-0.91 ; \mathrm{P}<0.001$ for other non-health professionals). In urban areas, caesarean birthing and receiving birthing assistance from non-health professionals, who were not TBAs, reduced the likelihood of initiating breastfeeding within $1 \mathrm{~h}$ of birth compared to vaginal birthing and receiving assistance from health professionals (AOR: 0.51, 95\% CI: $0.44-0.57 ; P<0.001$ for caesarean births and AOR: 0.81 , 95\% CI: $0.68-0.96$; $P=0.01$ for other nonhealth professionals). Rural mothers who attended 4 or more ANC visits were more likely to timely initiate breastfeeding (AOR: 1.48, 95\% CI: 1.36-1.60; $P<0.001$ ).

Among rural mothers, the likelihood of EIBF was increased in those who resided in the North-Eastern, Southern, Western and Eastern regions, similar to the results for the total population and urban residence [Table 3]. In urban areas, mothers in the North-Eastern, Western and Southern regions were more likely to breastfeed within the first hour post-birth compared to those in the Northern region (AOR: $2.46,95 \%$ CI: 1.60 3.79; P $<0.001$ for North-East; AOR: 1.63 , 95\% CI: $1.08-$ 2.46; $\mathrm{P}<0.001$ for West and AOR: 2.21, 95\% CI: $1.57-$ 3.09; $\mathrm{P}<0.001$ for South). Central region mothers were $33 \%$ less likely to timely breastfeed their babies compared to North region mothers (AOR: 0.67, 95\% CI: 0.49-0.91; $P=0.011$ ) [Table 3].

\section{Discussion}

Our study showed that $41.5 \%$ of Indian mothers initiated breastfeeding within 1-h post-birth. This proportion was almost similar to mothers who resided in both rural (41.0\%) and urban (42.9\%) areas, with substantial difference among mothers who resided in urban areas compared to those who lived in rural areas of India. The prevalence and likelihood of EIBF was highest in Indian mothers who reported frequent health service contacts and those with higher educational attainment, with minor differences in both rural and urban dwellers. The prevalence of EIBF varied in the regions of India. Residence in the Southern, Eastern, Western and NorthEastern regions were associated with EIBF practice in India. This was despite the fact that the North-East region had the lowest percentage of EIBF in all populations. Residing in rural areas of the Central region was associated with delayed EIBF. The present study found that birthing at home, by caesarean delivery or receiving delivery assistance from non-health professionals were associated with decreased likelihood of EIBF in all populations.

The present study showed that India's EIBF prevalence was well below the recommended level $(41.5 \%$ as against the expected 90\%). Nevertheless, it is important to note that India's current EIBF rate is due to the implementation of an array of national child health programmes (i.e., the National Health Mission in partnership with the Indian
Academy of Paediatrics and mass media campaigns) [15] that saw EIBF prevalence increase from $24.5 \%$ in 2006 [23] to $41.5 \%$ in 2016 . This improvement in EIBF prevalence demonstrates not only that infant feeding interventions that are context-specific could improve breastfeeding practices, but that well-coordinated child health programmes could make a significant impact in children's health and well-being in both the short- and long-term [8, 41].

Consistent with findings from a systematic review conducted for South Asia [42] and studies from India [43], Pakistan [44], Bangladesh [45] and Nepal [46], our study indicated that higher maternal educational attainment in the total population was associated with EIBF compared to those with no schooling. Evidence has shown that higher maternal education has significant impact on child nutrition and well-being [47-50]. This may be due to the increased receptivity of a mother with formal education to health promotion campaigns and their empowerment status within the household to make informed health-related decisions [51, 52]. The association between higher maternal educational attainment and EIBF highlights the wide-ranging importance of improving women's access to quality education, in line with the Sustainable Development Goal-4 (SDG-4), which aims to ensure that all girls and boys complete free, equitable and quality primary and secondary education by the year 2030 [53].

Difficulties in accessing health care services such as ANC have been shown to form significant barriers in initiating breastfeeding within the first hour of birth [54-56]. Our study indicated that receiving four or more ANC sessions was associated with increased likelihood of EIBF in the total population. This finding is consistent with previous studies conducted in Sri Lanka $[19,57]$, Nepal [46] and Bangladesh [58] which found that no or less than four ANC visits was associated with delayed EIBF. These findings suggest that the health messages provided during ANC sessions could improve mothers' adherence to the WHO breastfeeding recommendations [59]. For example, step 3 of the revised Baby-Friendly Hospital Initiative (BFHI) indicates that all pregnant women and their families should be informed of the importance and management of breastfeeding in ANC sessions [60]. Increasing ANC uptake would ensure improvements in India's BFHI, a global breastfeeding strategy to promote, protect and support optimal lactation among new mothers [61]. Between 2015 and 2018, the World Breastfeeding Trends Initiative - India (WBTi) scored the country zero out of 10 indicators used to assess the country's BFHI as there was no data on the total hospitals (both public \& private) and maternity facilities designated or reassessed as "Baby Friendly" in line with global criteria [62, 63]. This implies that 
efforts need to be made to realign or refine current breastfeeding programs (such as the Mother's Absolute Affection programme [64]) in line with global best practices.

Since the year 1997, improving ANC access has been a priority for the Government of India, where key strategic initiatives have resulted in free-of-charge maternal and child health services, as well as the 24-h operation of primary health care centres in the rural areas [65-67]. Despite these interventions in health service delivery, the utilisation of these services has been limited [24]. This is evident in the current study, with demographic data showing that $70.3 \%$ of urban mothers who initiated breastfeeding within 1-h of birth attended four or more ANC visits compared to $50.8 \%$ of rural mothers, further highlighting the disparities in health service utilisation in India. This finding is in line with previous studies which demonstrated wide rural-urban disparities in ANC utilisation in India $[68,69]$. The continued improvement in public health infrastructure in conjunction with the development of health programmes that aim to increase ANC utilisation will likely have a significant impact on EIBF and subsequent infant health in India.

The present study showed differences in rural-urban residence in relation to the increased likelihood of EIBF. Higher maternal education and frequent ANC $(\geq 4)$ visits were associated with EIBF among mothers residing in rural areas compared to those living in the urban areas. It is uncertain as to why mothers in rural compared to urban areas would be more inclined to timely initiate breastfeeding; however, government funded ruralspecific $\mathrm{MCH}$ interventions such as the NRHM - which aimed to address the health needs of under-served rural areas - may have played a role [21]. To our knowledge, this is the first study to consider the determining factors of EIBF in rural-urban settings in India. Therefore, further studies that explore the potential reasons for why rural mothers may be more likely to timely initiate breastfeeding compared to their urban counterparts are warranted.

Appropriate birthing-related circumstances are essential in encouraging mothers to timely initiate breastfeeding [42]. Our analysis showed that birthing in a health facility was associated with EIBF compared to home birthing, regardless of rural-urban residence. These results are consistent with the literature from Bangladesh [58], Sri Lanka [70] and Nepal [46]. In addition, delivery assisted by health professionals was associated with EIBF compared to TBAs or other non-health professionals' assisted delivery. Notably, the mode of delivery was also of great significance, with caesarean birthing potentially negating some of the positive effects of health facility birthing on EIBF practice. Consistent with previous Indian studies, as well as the broader literature [43, 71-
73], we found that caesarean birth was associated with delayed EIBF compared to vaginal birth. A recent systematic review has suggested that the impact of caesarean birth on EIBF may be due to the post-operative care that possibly disrupts the early skin-to-skin contact which supports EIBF [74]. Despite this challenge, evidence suggests that EIBF is feasible even after caesarean delivery if health professionals are well-trained to provide the necessary support and guidance to the mother $[75,76]$. It is, therefore, essential that initiatives aimed at increasing breastfeeding should include the training of health professionals and establishment of 'Baby Friendly' health facilities to appropriately support mothers to breastfeed within the first hour of birth [77].

The present study found that the odds of timely initiation of breastfeeding were highest in the North-East, South, East and West of India compared to the Northern region, irrespective of rural-urban residence. In contrast, the Central region was associated with delayed EIBF in both the total population and urban residence compared to the Northern region, which is consistent with previous studies conducted in India that found reduced odds of EIBF in the Central region of India [19, 43].The underlying reasons for the regional variations in EIBF practice have not yet been adequately elucidated in the literature. However, plausible reasons may be due to the local cultural attitudes such as the negative perceptions towards the use of the first milk (colostrum) [78], advice from mothers-in-law that does not promote optimal breastfeeding [42] and the mother's prenatal intention not to breastfeed [79]. In India, there is a need to provide region-specific policies and interventions that target mothers in their local communities, as well as the involvement of family members and community leaders in order to improve EIBF practice. Our analysis also indicated that higher father's education and being formerly or never married never were associated with delayed EIBF. Additional studies are needed to investigate the factors associated with regional variations of EIBF, as well as the impact of father's education status and marital status on EIBF in India.

\section{Study limitations and strengths}

The study has methodological limitations that should be considered. First, we used cross-section data for the study, indicating that a clear temporal association between the study factors and EIBF cannot be established. Second, the information on the study factors and outcome variable were based on self-reporting. This is a source of recall or measurement bias, which could result in an overestimation or underestimation of the association between the study factors and EIBF. Third, a lack of assessment of unmeasured confounding factors 
(instrumental vaginal birth, cultural reasons, health professional's knowledge of EIBF or family dynamics) may have affected the association between the primary and secondary outcomes.

Despite the limitations, the study has strengths. First, we believe that the possible effect of selection bias is unlikely to impact the study findings based on the nationally representative nature of the sample size and the high response rates (94-99.6\%). Second, the NFHS-4 data, including the study factors and EIBF were collected by trained personnel who used standardised questionnaires to ensure consistency across all Indian states and territories. Finally, our study provides relevant contextual evidence on key modifiable determinants of EIBF in one of the world's largest populations to advocate for appropriate policies and interventions that seek to promote EIBF practice in India.

\section{Conclusion}

Our study suggests that less than half of Indian mothers initiated breastfeeding within 1-h post-birth (41.5\%), with a significant difference in both rural and urban EIBF prevalence ( 41.0 and $42.9 \%$, respectively). Higher maternal education, frequent ANC visits, birthing in a health facility and residence in the North-East, South, West and East regions were associated with EIBF in India, regardless of rural-urban residence. In contrast, we found that mothers delayed breastfeeding after birth if they lived in the Central region, received delivery assistance from non-health professionals or gave birth through caesarean section. In India, it is essential that health promotion campaigns to improve EIBF should be region-specific and should focus on mothers with no schooling and those with limited access to healthcare facilities to maximise impacts.

\section{Additional file}

Additional file 1: Characteristics of the study population, 2015-2016 India NFHS. (DOCX $24 \mathrm{~kb})$

\section{Abbreviations}

BFHI: Baby-Friendly Hospital Initiative; DHS: Demographic and health survey; EIBF: Early initiation of breastfeeding; IIPS: International Institute for Population Sciences; NFHS: National Family and Health Survey;

NRHM: National Rural Health Mission; OR: Odds ratio; UNICEF: United Nations Children's Fund; WHO: World Health Organization

\section{Acknowledgements}

The authors are grateful to Measure DHS, ICF International, Rockville, Marylands, USA for providing the data for the analysis.

\section{Authors' contributions}

PS contributed to the conceptualisation of the study and data analyses, obtained the data, drafted the original manuscript, compiled and interpreted the results and critically revised the manuscript as submitted. EO contributed to the data interpretation and critical revision of the manuscript as submitted. FAO conceptualised the study, analysed the data, contributed to the interpretation of data, provided overall supervision and critically revised the manuscript as submitted. All authors read and approved the final manuscript as submitted.

\section{Funding}

This study received no specific grant from any funding agency in public, commercial or not-for-profit sectors.

\section{Availability of data and materials}

The analysis was based on the datasets collected for the India Demographic and Health Survey. Information on the data and content can be assessed at http://www.dhsprogram.com/data/available-datasets.cfm.

\section{Ethics approval and consent to participate}

The Ethics Review Board at the International Institute for Population Sciences, Mumbai, India granted Measure DHS/ICF International ethical approvals before the surveys were conducted, with written informed consent obtained from participants during the surveys. The questionnaires used for the survey were reviewed and approved by ICF International Institutional Review Board (IRB) to ensure they met the United States Department of Health and Human Services regulations for the protection of human participants, as well as the host country's IRB, to ensure compliance with national laws. Approval was sought from Measure DHS and permission was granted for this use.

\section{Consent for publication}

This article contains no personal data in any form.

\section{Competing interests}

FAO is an Editorial Board Member of BMC Public Health but did not play any role in the peer-review and decision making process for this manuscript. The other authors declare that they have no competing interests.

\section{Author details}

${ }^{1}$ Translational Health Research Institute (THRI), School of Medicine, Western Sydney University, Campbelltown Campus, Locked Bag 1797, Penrith, NSW 2571, Australia. ${ }^{2}$ Medical Education Unit, School of Medicine, Western Sydney University, Locked Bag 1797, Penrith, NSW 2571, Australia. ${ }^{3}$ Prescot Specialist Medical Centre, Welfare Quarters, Makurdi, Benue State, Nigeria.

Received: 16 July 2018 Accepted: 27 June 2019

Published online: 08 July 2019

\section{References}

1. Garcia CR, Mullany LC, Rahmathullah L, Katz J, Thulasiraj RD, Sheeladevi S, et al. Breast-feeding initiation time and neonatal mortality risk among newborns in South India. J Perinatol 2011;31(6):397-403. Epub 2010/12/18. doi: https://doi.org/10.1038/jp.2010.138. PubMed PMID: 21164424.

2. Edmond KM, Zandoh C, Quigley MA, Amenga-Etego S, Owusu-Agyei S, Kirkwood BR. Delayed breastfeeding initiation increases risk of neonatal mortality. Pediatrics. 2006;117(3):e380-e386. Epub 2006/03/03. doi: https:// doi.org/10.1542/peds.2005-1496. PubMed PMID: 16510618.

3. Mullany LC, Katz J, Li YM, Khatry SK, LeClerq SC, Darmstadt GL, et al. Breastfeeding patterns, time to initiation, and mortality risk among newborns in southern Nepal. J Nutr 2008;138(3):599-603. Epub 2008/02/22. doi: https:// doi.org/10.1093/jn/138.3.599. PubMed PMID: 18287373; PubMed Central PMCID: PMCPMC2366167.

4. Debes AK, Kohli A, Walker N, Edmond K, Mullany LC. Time to initiation of breastfeeding and neonatal mortality and morbidity: a systematic review. BMC Public Health. 2013;13 Suppl 3:S19. Epub 2014/02/26. doi: https://doi. org/10.1186/1471-2458-13-S3-S19. PubMed PMID: 24564770; PubMed Central PMCID: PMCPMC3847227.

5. Turfkruyer $M$, Verhasselt V. Breast milk and its impact on maturation of the neonatal immune system. Curr Opin Infect Dis. 2015;28(3):199-206.

6. Wang $H$, Bhutta AZ, Coates MM, Coggeshall M, Dandona L, Diallo K, et al. Global, regional, national, and selected subnational levels of stillbirths, neonatal, infant, and under-5 mortality during 1980-2015: a systematic analysis for the global burden of disease study 2015. Lancet. 2016;388:1725-74 
7. NEOVITA Study Group. Timing of initiation, patterns of breastfeeding, and infant survival: prospective analysis of pooled data from three randomised trials. Lancet Glob Health. 2016;4(4):e266-e75.

8. Victora CG, Bahl R, Barros AJ, França GV, Horton S, Krasevec J, et al. Breastfeeding in the 21 st century: epidemiology, mechanisms, and lifelong effect. Lancet. 2016;387(10017):475-90.

9. Ogbo FA, Agho K, Ogeleka P, Woolfenden S, Page A, Eastwood J. Infant feeding practices and diarrhoea in sub-Saharan African countries with high diarrhoea mortality. PLoS One. 2017;12(2):e0171792.

10. Agho KE, Ogeleka P, Ogbo FA, Ezeh OK, Eastwood J, Page A. Trends and predictors of prelacteal feeding practices in Nigeria (2003-2013). Nutrients. 2016;8(8):462.

11. Khan J, Vesel L, Bahl R, Martines JC. Timing of breastfeeding initiation and exclusivity of breastfeeding during the first month of life: effects on neonatal mortality and morbidity - a systematic review and meta-analysis. Matern Child Health J. 2015;19(3):468-79.

12. United Nations Children's Fund. Tracking Progress for Breastfeeding Policies and Programmes. New York: 2017.

13. Takahashi K, Ganchimeg T, Ota E, Vogel JP, Souza JP, Laopaiboon M, et al. Prevalence of early initiation of breastfeeding and determinants of delayed initiation of breastfeeding: secondary analysis of the WHO global survey. Sci Rep. 2017;7:44868.

14. Jones G, Steketee RW, Black RE, Bhutta ZA, Morris SS, Group BCSS. How many child deaths can we prevent this year? Lancet. 2003;362(9377):65-71.

15. Aguayo VM, Gupta G, Singh G, Kumar R. Early initiation of breast feeding on the rise in India. BMJ Glob Health 2016;1(2):e000043. Epub 2017/06/08. doi: https://doi.org/10.1136/bmjgh-2016-000043. PubMed PMID: 28588936; PubMed Central PMCID: PMCPMC5321339.

16. Patel A, Banerjee A, Kaletwad A. Factors associated with prelacteal feeding and timely initiation of breastfeeding in hospital-delivered infants in India. J Hum Lact. 2013;29(4):572-8.

17. Sharma A, Thakur PS, Tiwari R, Kasar PK, Sharma R, Kabirpanthi V. Factors associated with early initiation of breastfeeding among mothers of tribal area of Madhya Pradesh, India: a community based cross sectional study. International Journal of Community Medicine and Public Health. 2017;3(1): 194-9.

18. Badaya N, Jain S, Kumar N. Time of initiation of breastfeeding in various modes of delivery and to observe the effect of low birth weight and period of gestation on initiation of breastfeeding. International Journal of Contemporary Pediatrics. 2018;5(4):1509-17.

19. Dibley MJ, Roy SK, Senarath U, Patel A, Tiwari K, Agho KE, et al. Acrosscountry comparisons of selected infant and young child feeding indicators and associated factors in four south Asian countries. Food Nutr Bull 2010; 31(2):366-375. Epub 2010/08/17. doi: https://doi.org/10.1177/156482651 003100224. PubMed PMID: 20707239.

20. Maternal and Child Health Integrated Program. India's Reproductive, Maternal, Newborn, Child, and Adolescent Health (RMNCH+A) Strategy Online: Maternal and Child Health Integrated Program; 2014 [cited 2019 May 28]. Available from: https://www.mchip.net/sites/default/files/RMNCH+ A\%20in\%20India.pdf.

21. Gupta M, Angeli F, van Schayck OC, Bosma H. Effectiveness of a multiplestrategy community intervention to reduce maternal and child health inequalities in Haryana, North India: a mixed-methods study protocol. Glob Health Action. 2015;8(1):25987.

22. O'Neil S, Naeve K, Ved R. An examination of the maternal health quality of care landscape in India. Chicago, IL: Mathematica Policy Research; 2017.

23. International Institute for Population Sciences (IIPS), Macro International. National Family Health Survey (NFHS-3), 2005-06. Mumbai, India IIPS., 2007.

24. International Institute for Population Sciences (IIPS), ICF. National Family Health Survey (NFHS-4), Andhra Pradesh. Mumbai, India IIPS., 2018.

25. International Institute for Population Sciences (IIPS), ICF. National Family Health Survey (NFHS-4), West Bengal. Mumbai, India IIPS, 2017.

26. International Institute for Population Sciences (IIPS), ICF. National Family Health Survey (NFHS-4), Bihar. Mumbai, India IIPS, 2017.

27. Barik D, Thorat A. Issues of unequal access to public health in India. Front Public Health. 2015:3:245.

28. Mitra A, Murayama M. Rural to urban migration: a district-level analysis for India. International Journal of Migration, Health and Social Care. 2009;5(2): 35-52.

29. Patil AV, Somasundaram K, Goyal R. Current health scenario in rural India. Aust J Rural Health. 2002;10(2):129-35.
30. Balarajan Y, Selvaraj S, Subramanian S. Health care and equity in India. Lancet. 2011;377(9764):505-15.

31. Government of India - Ministry of Home Affairs, Office of the Registrar General \& Census Commissioner India. Online: Office of the Registrar General \& Census Commissioner, India; 2019 [cited 2019 May 28]. Available from: http://censusindia.gov.in/2011-Common/CensusData2011.html.

32. Agho KE, Ezeh OK, Ogbo FA, Enoma Al, Raynes-Greenow C. Factors associated with inadequate receipt of components and use of antenatal care services in Nigeria: a population-based study. Int Health. 2018;10(3): 172-81.

33. World Health Organization. Indicators for assessing infant and young child feeding practices. Geneva, Switzerland; 2008.

34. Ogbo FA, Eastwood J, Page A, Efe-Aluta O, Anago-Amanze C, Kadiri EA, et al. The impact of sociodemographic and health-service factors on breastfeeding in sub-Saharan African countries with high diarrhoea mortality. Public Health Nutr. 2017;20(17):3109-19.

35. Ogbo FA, Agho KE, Page A. Determinants of suboptimal breastfeeding practices in Nigeria: evidence from the 2008 demographic and health survey. BMC Public Health. 2015:15:259.

36. Chandhiok N, Singh KJ, Sahu D, Singh L, Pandey A. Changes in exclusive breastfeeding practices and its determinants in India, 1992-2006: analysis of national survey data. Int Breastfeed J. 2015;10(1):34

37. Filmer D, Pritchett LH. Estimating wealth effects without expenditure data-or tears: an application to educational enrollments in states of India. Demography. 2001;38(1):115-32.

38. Ogbo FA, Page A, Idoko J, Agho KE. Population attributable risk of key modifiable risk factors associated with non-exclusive breastfeeding in Nigeria. BMC Public Health. 2018;(18):247. https://doi.org/10.1186/s12889-018-5145-y.

39. World Health Organization. Primary health care, report of the international conference on primary health care, Alma-Ata, USSR, 6-12 September, 1978. Geneva, Switzerland; 1978.

40. International Institute for Population Sciences (IIPS), ICF. National Family Health Survey (NFHS-4), India. Mumbai, India IIPS, 2017.

41. Horta BL, Loret de Mola C, Victora CG. Long-term consequences of breastfeeding on cholesterol, obesity, systolic blood pressure and type 2 diabetes: a systematic review and meta-analysis. Acta Paediatr. 2015; 104(S467):30-7.

42. Sharma IK, Byrne A. Early initiation of breastfeeding: a systematic literature review of factors and barriers in South Asia. Int Breastfeed J 2016;11:17. Epub 2016/06/23. doi: https://doi.org/10.1186/s13006-016-0076-7. PubMed PMID: 27330542; PubMed Central PMCID: PMCPMC4912741.

43. Patel A, Badhoniya N, Khadse S, Senarath U, Agho KE, Dibley MJ, et al. Infant and young child feeding indicators and determinants of poor feeding practices in India: secondary data analysis of National Family Health Survey 2005-06. Food Nutr Bull 2010;31(2):314-333. Epub 2010/08/17. doi: https:// doi.org/10.1177/156482651003100221. PubMed PMID: 20707236.

44. Ali S, Ali SF, Imam AM, Ayub S, Billoo AG. Perception and practices of breastfeeding of infants 0-6 months in an urban and a semi-urban community in Pakistan: a cross-sectional study. J Pak Med Assoc 2011;61(1): 99-104. Epub 2012/03/01. PubMed PMID: 22368919.

45. Rahman M, Haque SE, Zahan S, Islam O. Noninstitutional births and newborn care practices among adolescent mothers in Bangladesh. J Obstet Gynecol Neonatal Nurs 2011;40(3):262-273. Epub 2011/05/19. doi: https:// doi.org/10.1111/j.1552-6909.2011.01240.x. PubMed PMID: 21585526.

46. Subedi N, Paudel S, Rana T, Poudyal AK. Infant and young child feeding practices in Chepang communities. J Nepal Health Res Counc 2012;10(21): 141-146. Epub 2012/10/05. PubMed PMID: 23034377.

47. Afnan-Holmes H, Magoma M, John T, Levira F, Msemo G, Armstrong CE, et al. Tanzania's countdown to 2015: an analysis of two decades of progress and gaps for reproductive, maternal, newborn, and child health, to inform priorities for post-2015. Lancet Glob Health. 2015;3(7):e396-409.

48. Requejo JH, Bhutta ZA. The post-2015 agenda: staying the course in maternal and child survival. Arch Dis Child. 2015;100(Suppl 1):S76-81.

49. Ahmed S, Creanga AA, Gillespie DG, Tsui AO. Economic status, education and empowerment: implications for maternal health service utilization in developing countries. PLoS One. 2010;5(6):e11190.

50. Ogbo FA, Dhami MV, Awosemo AO, Olusanya BO, Olusanya J, Osuagwu UL, et al. Regional prevalence and determinants of exclusive breastfeeding in India. Int Breastfeed J. 2019;14:20.

51. Acharya $P$, Khanal $V$. The effect of mother's educational status on early initiation of breastfeeding: further analysis of three consecutive Nepal 
demographic and health surveys. BMC Public Health 2015;15:1069. Epub 2015/10/21. doi: https://doi.org/10.1186/s12889-015-2405-y. PubMed PMID 26482789; PubMed Central PMCID: PMCPMC4610048.

52. Ogbo FA, Page A, Agho KE, Claudio F. Determinants of trends in breastfeeding indicators in Nigeria, 1999-2013. Public Health Nutr. 2015;18:3287-99.

53. United Nations. Sustainable development goals: United Nations; 2016 [cited 201615 march]. Available from: http://www.un.org/ sustainabledevelopment/sustainable-development-goals/.

54. Goldie SJ, Sweet S, Carvalho N, Natchu UC, Hu D. Alternative strategies to reduce maternal mortality in India: a cost-effectiveness analysis. PLoS Med 2010;7(4):e1000264. Epub 2010/04/28. doi: https://doi.org/10.1371/journal. pmed.1000264. PubMed PMID: 20421922; PubMed Central PMCID: PMCPMC2857650.

55. Darmstadt GL, Bhutta ZA, Cousens S, Adam T, Walker N, de Bernis $L$, et al. Evidence-based, cost-effective interventions: how many newborn babies can we save? Lancet. 2005;365(9463):977-988. Epub 2005/03/16. doi: https:// doi.org/10.1016/S0140-6736(05)71088-6. PubMed PMID: 15767001.

56. Adam T, Lim SS, Mehta S, Bhutta ZA, Fogstad H, Mathai M, et al. Cost effectiveness analysis of strategies for maternal and neonatal health in developing countries. BMJ. 2005:331(7525):1107. Epub 2005/11/12. doi: https://doi.org/10.1136/bmj.331.7525.1107. PubMed PMID: 16282407; PubMed Central PMCID: PMCPMC1283271.

57. Senarath U, Dibley MJ, Godakandage SS, Jayawickrama H, Wickramasinghe A, Agho KE, et al. Determinants of infant and young child feeding practices in Sri Lanka: secondary data analysis of demographic and health survey 2000. Food Nutr Bull 2010;31(2):352-365. Epub 2010/08/17. doi: https://doi. org/10.1177/156482651003100223. PubMed PMID: 20707238.

58. Mihrshahi S, Kabir I, Roy SK, Agho KE, Senarath U, Dibley MJ, et al. Determinants of infant and young child feeding practices in Bangladesh: secondary data analysis of demographic and health survey 2004. Food Nutr Bull 2010;31(2):295-313. Epub 2010/08/17. doi: https://doi.org/10.1177/1564 82651003100220. PubMed PMID: 20707235.

59. Renkert S, Nutbeam D. Opportunities to improve maternal health literacy through antenatal education: an exploratory study. Health Promot Int 2001; 16(4):381-388. Epub 2001/12/06. PubMed PMID: 11733456.

60. World Health Organization. Implementation guidance: protecting, promoting and supporting breastfeeding in facilities providing maternity and newborn services - the revised baby-friendly hospital initiative. Geneva World Health Organization; 2018. Contract No.: CC BY-NC-SA 3.0 IGO

61. World Health Organisation, United Nation Childen Education Fund. Babyfriendly hospital initiative revised, updated and expanded for integrated care. Geneva, Switzerland: WHO Document Production Services; 2009.

62. Breastfeeding Promotion Network of India (BPNI), International Baby Food Action Network (IBFAN) Asia. Arrested Development. All is not well with our children's health - assessment of India's policy and Programmes on infant and young child feeding Delhi. India: World Breastfeeding Trends Initiative (WBTi; 2015

63. Breastfeeding Promotion Network of India (BPNI), International Baby Food Action Network (IBFAN) Asia. Arrested Development: 5th Report of Assessment of India's Policy and Programmes on Infant and Young Child Feeding Delhi, India: World Breastfeeding Trends Initiative (WBTi) 2018.

64. Monalisha S. Exclusive breastfeeding - mothers absolute affection. Acta Scientific Medical Sciences. 2018;2(8):1-2.

65. Ministry of Health and Family Welfare (MOHFW). Reproductive and child health Programme: schemes for implementation. New Delhi, India: Department of Family Welfare, MOHFW; 1997.

66. Ministry of Health and Family Welfare (MOHFW). National Health Policy. New Delhi, India: Department of Family Welfare, MOHFW; 2002. p. 2002.

67. Ministry of Health and Family Welfare (MOHFW). National population policy. New Delhi, India: Department of Family Welfare, MOHFW; 2000. p. 2000.

68. Singh A, Pallikadavath S, Ram F, Ogollah R. Inequalities in advice provided by public health workers to women during antenatal sessions in rural India. PLoS One 2012;7(9):e44931. Epub 2012/10/03. doi: https://doi.org/10.1371/ journal.pone.0044931. PubMed PMID: 23028688; PubMed Central PMCID: PMCPMC3444494

69. Pallikadavath S, Foss M, Stones RW. Antenatal care: provision and inequality in rural North India. Soc Sci Med 2004;59(6):1147-1158. Epub 2004/06/24. doi: https://doi.org/10.1016/j.socscimed.2003.11.045. PubMed PMID: 15210087
70. Senarath U, Siriwardena I, Godakandage SS, Jayawickrama H, Fernando DN, Dibley MJ. Determinants of breastfeeding practices: an analysis of the Sri Lanka demographic and health survey 2006-2007. Matern Child Nutr 2012; 8(3):315-329. Epub 2011/04/22. doi: https://doi.org/10.1111/j.1740-8709.2 011.00321.x. PubMed PMID: 21507202.

71. Takahashi K, Ganchimeg T, Ota E, Vogel JP, Souza JP, Laopaiboon M, et al. Prevalence of early initiation of breastfeeding and determinants of delayed initiation of breastfeeding: secondary analysis of the WHO global survey. Sci Rep 2017;7:44868. Epub 2017/03/23. doi: https://doi.org/10.1038/srep44868. PubMed PMID: 28322265; PubMed Central PMCID: PMCPMC5359598.

72. Karlstrom A, Lindgren $\mathrm{H}$, Hildingsson I. Maternal and infant outcome after caesarean section without recorded medical indication: findings from a Swedish case-control study. BJOG. 2013;120(4):479-486; discussion 86. Epub 2013/01/16. doi: https://doi.org/10.1111/1471-0528.12129. PubMed PMID: 23316937.

73. Bodner K, Wierrani F, Grunberger W, Bodner-Adler B. Influence of the mode of delivery on maternal and neonatal outcomes: a comparison between elective cesarean section and planned vaginal delivery in a low-risk obstetric population. Arch Gynecol Obstet 2011;283(6):1193-1198. Epub 2010/05/28. doi: https://doi.org/10.1007/s00404-010-1525-y. PubMed PMID: 20505947.

74. Prior E, Santhakumaran S, Gale C, Philipps LH, Modi N, Hyde MJ. Breastfeeding after cesarean delivery: a systematic review and meta-analysis of world literature. Am J Clin Nutr 2012:95(5):1113-1135. Epub 2012/03/30. doi: https://doi.org/10.3945/ajcn.111.030254. PubMed PMID: 22456657.

75. Rollins NC, Bhandari N, Hajeebhoy N, Horton S, Lutter CK, Martines JC, et al. Why invest, and what it will take to improve breastfeeding practices? Lancet. 2016;387(10017):491-504. Epub 2016/02/13. doi: https://doi.org/10.1 016/S0140-6736(15)01044-2. PubMed PMID: 26869576

76. Ogbo FA, Eastwood J, Page A, Arora A, McKenzie A, Jalaludin B, et al. Prevalence and determinants of cessation of exclusive breastfeeding in the early postnatal period in Sydney, Australia. Int Breastfeed J. 2017;12:16.

77. Desai G, Anand A, Modi D, Shah S, Shah K, Shah A, et al. Rates, indications, and outcomes of caesarean section deliveries: a comparison of tribal and non-tribal women in Gujarat, India. PLoS One 2017;12(12):e0189260. Epub 2017/12/28. doi: https://doi.org/10.1371/journal.pone.0189260. PubMed PMID: 29281645: PubMed Central PMCID: PMCPMC5744934.

78. Bandyopadhyay M. Impact of ritual pollution on lactation and breastfeeding practices in rural West Bengal, India. Int Breastfeed J. 2009:4:2. Epub 2009/ 03/28. doi: https://doi.org/10.1186/1746-4358-4-2. PubMed PMID: 19323839; PubMed Central PMCID: PMCPMC2667394.

79. Jain S, Thapar RK, Gupta RK. Complete coverage and covering completely: breast feeding and complementary feeding: knowledge, attitude, and practices of mothers. Med J Armed Forces India 2018;74(1):28-32. Epub 2018/02/02. doi: https://doi.org/10.1016/j.mjafi.2017.03.003. PubMed PMID: 29386728; PubMed Central PMCID: PMCPMC5771780.

\section{Publisher's Note}

Springer Nature remains neutral with regard to jurisdictional claims in published maps and institutional affiliations.

Ready to submit your research? Choose BMC and benefit from:

- fast, convenient online submission

- thorough peer review by experienced researchers in your field

- rapid publication on acceptance

- support for research data, including large and complex data types

- gold Open Access which fosters wider collaboration and increased citations

- maximum visibility for your research: over $100 \mathrm{M}$ website views per year

At $\mathrm{BMC}$, research is always in progress.

Learn more biomedcentral.com/submissions 